Instant messaging: A novel means of facilitating the participation of hard-to-reach groups in sensitive topic research

\begin{tabular}{|r|l|}
\hline Journal: & Qualitative Research Journal \\
\hline Manuscript ID & QRJ-06-2020-0061.R1 \\
\hline Manuscript Type: & Research Paper \\
\hline Keywords: & Sex work, Sensitive topic, Technology, Hard-to-reach groups \\
\hline \multicolumn{2}{|l}{} \\
\hline
\end{tabular}

SCHOLARONE $^{\text {tw }}$

Manuscripts 


\section{Instant messaging: A novel means of facilitating the participation of hard-to-reach groups in sensitive topic research}

\section{Purpose}

As society becomes ever more reliant on internet technology for everyday communications, this paper explores the use of Instant Messaging (IM) in qualitative research. Discussed within the context of sensitive topic research with potentially hidden and hard-to-reach groups, the purpose of this paper is to discuss the value of adaptive and contemporary research approaches which facilitate participation on the terms of the participant.

\section{Approach}

Reflecting on the data collection process from the primary authors $\mathrm{PhD}$ research, this paper critically considers some of the issues raised by IM facilitated semi-structured interviews.

\section{Findings}

This paper raises a number of issues, including how the perceived depth of participant response is influenced by their brevity, resultant of the space between parties which allows for considered and concise communication. This disconnect, created by the use of technology, also has implications for the power relations between researcher and participant, and the ability to identify the non-verbal cues which communicate emotion and sentiment.

\section{Value}

This paper highlights that whilst limited in some respects, an IM facilitated interview provides a unique platform through which hidden and hard-to-reach groups may be empowered to participate in research, which they may otherwise avoid. 


\section{Context:}

Hidden and hard-to-reach groups are terms that are often used interchangeably but seldom definitively defined. There are, however, some indicative characteristics shared by such populations. These might include, small population size and/or populations that are relatively widely dispersed; groups that experience acute socio-economic deprivation; those that are socially invisible; those that experience cultural or ideological and language barriers; and importantly, in the context of this study, have distinctive service needs and a suspicion of the police (Jones and Newburn, 2001). Therefore, whilst caution needs to be exercised around ensuring such terms do not become stigmatising, the identification of such characteristics aid researchers in their endeavours to understand some of the complexities in developing appropriate methodologies. This may be particularly important where the hidden or hard-toreach group remains wary of research attention from perceived 'outsiders' (Dewey and Heineman, 2013). This paper argues the importance of research respecting this position, and of striving to provide an environment in which the target demographic feels enabled to participate and have their voices heard. As primary author, this paper reflects upon the data collection process of my PhD study which took place between August 2018 and February 2019, and as such, will be presented from my perspective. I suggest that Instant Messaging (hereafter referred to as $I M$ ) provides a means by which hidden and hard-to-reach groups are empowered to participate in research, which they may otherwise avoid.

The research study aims to understand the reporting behaviour of male sex workers who experience violence or other harmful behaviours. The male role within sexual commerce has typically been understood as the purchaser of services, with dominant discourses favouring discussions which limit the focus on male sex workers. Indeed, within the policy context in England and Wales, much of the approach is informed by a radical feminist discourse (see Home Office, 2004; 2006), and presents sex work as an issue of violence against women and 
children, primarily perpetrated by men (Whowell, 2010). This is despite the consistent finding that men make up at the very least, a significant minority of those selling sexual services in England and Wales, particularly when mapping the online market (see Sagar et al., 2014; Sanders et al., 2018). This focus on women has meant an emphasis on their support needs, rendering there scant support available for male sex workers nationally (Bryce et al., 2015). With this, and a policy framework which places the male role as primarily that of driving the demand sex work (see Home Office, 2008), men within the industry often go under acknowledged, under supported and under protected.

Male sex workers in England and Wales, like their female counterparts, are subject to a legal premise best described as foggy. The sale of sexual services between consenting adults, albeit legal in itself, is constricted by related offences which mean that many interactions between a sex worker and client will involve a criminal action (Pitcher and Wijers, 2014). Coupled with this legal complexity, is the idea that sex work stigma is combined with the assumption that male sex workers exhibit sexual behaviour with other men, amplifying the stigma faced by male sex workers (Minichiello, Scott and Callander, 2013). Resultant of these issues, many sex workers do not disclose their work (Weitzer, 2018; Pitcher, 2015). Therefore, there is some challenge in both identifying and successfully building research relations with men involved in sex work. What has been apparent is the importance of utilising adaptive and contemporary approaches to research, which both respect the position within which sex work sits socially and provides a platform for sex worker voices which is flexible enough to facilitate preferable conditions of participation.

Methods:

Despite focusing predominantly on female sex workers, a consideration of the methodological approaches of the existing sex work related literature is nonetheless important 
in developing a framework conducive to an ethical and valuable study, mindful of the reality faced by many of those who transact sex. Drawing upon existing approaches, and acknowledging that those invited to be involved in the research are experts in their own reality, the methodological approach of this study drew upon forms of Participatory Action Research (PAR) and consulted sex workers at every stage of its formation. A PAR approach facilitates knowledge co-construction, rather than maintaining traditional researcher-led notions (O’Neill, 2010). This links to feminist methodologies and principles of gender equality, using participatory methods and supporting the researcher to engage with structural inequalities and issues of power (Fine, 2007; Krumer-Nevo, 2009). Sex worker voices were not just present within the data generated but were also fundamental to the development of the questions being asked themselves (Van Der Meulen, 2011).

The study was structured into four phases, beginning with an online survey developed with the consultation of two male sex workers, support services and academics. The survey informed three later phases, involving interviews with male sex workers, support service practitioners and the police. For this initial phase, the sampling strategy involved a Twitter campaign, designed to reach potential participants through my established network of followers. Bearing similarities to a snowball sampling approach, the strategy relied on the endorsement or 'retweeting' of the study by other Twitter users, who essentially were able to utilise their established online presence to assist in reaching those within their network who may have been interested in participating.

Ethical approval was secured from the host institution. In addition, with reference to the vulnerability and difficulties of working with hidden and hard-to-reach groups, recruitment was defined by participatory principles, beneficence, non-maleficence and informed consent. An information sheet and consent form were sent via the participant's preferred mode of contact (email, IM) and all data was stored according to GDPR. 
The Use of Semi-structured Interviews:

Phase Two of the research involved exploring the views and experiences of men who had at some point sold or transacted sex in more detail. Given my own status as an outsider, and my relative naivety to the reality faced by these men, I deemed a flexible conversation based upon these experienced voices to be the most appropriate approach to learning more about their reality. I adopted a semi-structured interview technique in line with previous research informed theoretically by feminist approaches, which highlight the insensitivity and rigidness of more structured and 'masculine' data collection methods which do not address the potential power issues between the researcher and participant (Punch, 2014). The flexible nature of a semi-structured approach encourages divergence and exploration within a conversation, both acknowledging the researchers position as being limited to the facilitator of discussion and respecting the position of the participant as expert of their own reality (Fedyuk and Zentai, 2018; Campbell, 2016).

Furthermore, modern conversations are held in more ways than ever before, and as a society we are becoming far less limited to traditional notions of face to face contact. With this reality and the potential difficulty in reaching participants considered, I took a flexible approach to delivering the semi-structured interviews. Participants had the opportunity to engage by meeting face to face, through video call, over the telephone and over text through IM or email. Each method of delivery followed the same interview guide, and there were only slight procedural differences.

IM Interviews and case study:

On many modern IM interfaces, users have access to their messages at all times through their smart devices. IM has become less associated with synchronous conversation, and more 
synonymous with continuous sporadic conversation. Differing to other forms of electronic conversation, an IM is designed to mimic real life conversation and individual messages between users are often brief.

There are multiple ways of communicating available through IM, including via text, images and screenshots, GIFs, Emoji and other multimedia. I was able to send documents required for informed consent, and any other relevant information, without leaving the apps interface. The participant and I also had multiple methods of expressing ourselves within the conversation, which are discussed in further detail below.

The interview primarily reflected on here, was with a 39-year-old participant, given the pseudonym Nathan. I contacted Nathan just after he had followed my professional account, through Twitter's direct messaging service. I asked whether he would be interested in hearing more about the research, and consequently he agreed to take part in an interview. I then outlined the various means in which we could continue our conversation, and Nathan, conscious of his anonymity, highlighted that communicating via email would be preferable. Nathan however, raised his concern that his email address would identify his real full name, whereas his Twitter account used a pseudonym. I felt that offering him complete peace of mind may improve his trust in both the research and me, so I offered to continue our conversation through Twitter. An email or IM conversation using a different platform would have borne great similarity to Twitter direct messaging in that we would be communicating asynchronously via text online; but by keeping contact through the already established channel, Nathan remained anonymous. Our messages were sporadic in nature, with the conversation taking place over a number of days. We did not allocate time specifically for the interview as would have been the case with meeting face to face or calling via telephone or Skype, but instead we replied to the other's messages when we could, as we might have done with any other mobile conversation. By using the Twitter application on my mobile phone, I was notified directly of any new 
messages from Nathan. For much of the interview I was on a short break at a holiday park, and despite the patchy signal at that location, we maintained the conversation throughout the weekend. Despite my fear of the interview becoming frustrating for Nathan, with the conversation heading into the back end of the weekend, we covered the intended schedule and addressed further issues which were raised during the interview. Nathan commented that it was 'nice to have a chat about it' as he 'don't often get the chance', before sending me a screen shot of a message which he deemed to be from a potentially risky prospective client after the interview guide had been covered.

Deeply concise discussion:

Qualitative research effectively addresses the 'natural setting' and explores lived experiences of individuals in great depth and detail (Creswell, 2009). This natural setting now includes the widespread use of digital messaging across a range of platforms. One of the concerns that I had going into an IM interview surrounded the level of detail which the participant would relay, compared to more traditional means. Although our conversation was not bound by character limits, as public tweets are, responses tended to be limited to a few sentences. This was particularly noticeable when compared to data collected during a telephone interview, with a superficial consideration of the length of the two transcripts suggesting that the IM interview may lack depth. Indeed, the word count for the IM interview stood at 3376 words, whereas the telephone interview contained 7449.

The length of the transcript and the depth of discussion are not congruent however, given IM chat by its very nature is a shortened variation of communication, with users often sending messages which include abbreviations and 'text speak'. For example, an IM user may use 'IMO' instead of 'in my opinion' or 'TBH' in place of 'to be honest'. The responses within the IM interview, rather than lacking depth, were simply concise. 
Previous research on IM interviewing has noted that it is within the etiquette of the method to expect a delay between the question and answer, often because of the time it takes to type a response (Fontes and O’Mahoney, 2008). The asynchronous nature of IM conversation dictates that a participant is afforded space between question and answer, where they are able to consider their response and amend where applicable.

In contrast, the pause between question and response within the telephone interview was more limited, giving the respondent less time to consider their answer and no facility to immediately amend their spoken word [1]. Reflecting on the telephone interview, there were a number of instances where the participant had begun talking, before stopping mid-sentence and changing the direction of their narrative. This was not common within the IM interview, where Nathan had the time to ponder his response, review his typed text and make amendments before sending the message. Nathan's narrative may have appeared to be limited in terms of depth when viewed superficially, however in actuality the quality of the data gained was largely similar to the telephone interview, once transcribed and analysed.

Importantly within the IM interview, the space which facilitated a more thought out response from the participant was also offered to me as researcher. This meant that any follow up questions were well considered, as I had time to ponder Nathan's response and develop a pathway which would encourage further discussion (Partington, 2001). Rubin and Rubin (2005) discuss how follow up questions can also be introduced in later interviews once the researcher has transcribed and reviewed the data, noting areas which could be explored in more detail. One advantage of the IM interview format is that the transcript is saved within the chat, is readily available during the interview and can be reviewed as the discussion continues. The reflections which may have been raised post interview, as in the telephone interview, could therefore be raised whilst an IM participant is still engaged within the discussion. 
With space available to review the data and contemplate any follow up response, it is reasonable to argue that any output which digressed from the interview schedule would assume a certain considered quality, which perhaps the more spontaneous response of the telephone interview assumed in lesser quantity. Although at a superficial level there may be questions raised about just how much depth of discussion the IM interview may encourage, the space created by the disconnect between parties supported a valuable discussion, with the conversation delving into topics and producing data of a rich quality, whilst holding on to an element of considered brevity.

\section{Language beyond words:}

Mariampolski (2001) suggests that body language and other non-verbal communications are essential to human interaction, expressing approval, emotion, interest and comfort, often without intending to. Of particular significance to this research were non-verbal cues which may have suggested discomfort. The nature of the subject matter and the potential for the interview to delve into sensitive and perhaps upsetting topics required my specific vigilance to signs of distress (Silverman, 2000). Rodriguez (2018) highlights the observation of non-verbal communications as being key to a better understanding of participant experience within sensitive topic research, therefore questions may be raised about just how appropriate an IM based interview may be for such research.

Evidently an IM approach cannot provide the same level of expression through body language as face to face interaction would, with both parties involved in the interview separated by the technology (Aida, Faruz Ain and Woolard, 2019). Though unexpectedly, perhaps naively so given my own daily interaction with online communication, Nathan and I were able to communicate a body language of sorts through the medium of Emoji. Emoji are images which depict a variety of facial expressions, actions, items and symbols, which are available to 
the majority of smartphone users. The true value of Emoji is that they are able to 'convey a complexity of emotions that cannot translate easily into words' (Alismail and Zhang, 2018: 3367). There are limits to the expression of emotion within a typed message, with the text open to the interpretation of the receiving party. The inclusion of an Emoji, although also open to the interpretation of the receiving party, gives some indication of the nature of the message being sent outside of the written word (Durante, 2016).

Both Nathan and I made use of Emoji to express certain characteristics of our narrative which would likely not have come across in plain text. For example, when describing advertising his services online, Nathan said:

A lot of us have to make our own content.. my selfie skills are amazing compared to 2 years ago [2]

The first emoji, understood to be 'the face with tears of joy' was voted as the word of the year in 2015 by Oxford Dictionaries (Time, 2015), signalling the light-hearted nature of this excerpt of the conversation. The second, named as the 'man facepalming' emoji, has often been interpreted as resembling the popular online saying of 'SMH' or 'shaking my head' and is synonymous with a feeling of embarrassment or perhaps disbelief (Emojipedia, 2019a). The combination of the two Emoji may somewhat demonstrate the friendliness of the conversation, and also provide the reader an indication beyond the typed word as to the emotion with which Nathan had sent the message. My own interpretation of the Emoji use places Nathan as disbelieving of his own participation in 'selfies' or rather, good 'selfies', and perhaps indicates some level of perception that this behaviour transgresses some masculine stereotypes, with 'selfie' taking more commonly associated with more feminised identities (Dhir et al., 2016). 
Another example of our use of Emoji came when I asked Nathan to describe sex worker - police relations. Before discussing the fact that he had never been in contact with the police himself, and that he felt that the police would rather focus their attentions on 'dealers \& traffickers', Nathan highlighted where his work might sit on the spectrum of the sex industry:

At my end of the industry which I guess is mid to high end..?

The expression beyond typed words used by Nathan here, is described by Emojipedia as the 'man shrugging' Emoji (2019b). Shrugging one's shoulders is typically understood to demonstrate indifference or indecision. Although the exact meaning is again open to the interpretation of the reader, my understanding of the use of Emoji here is that Nathan was demonstrating a degree of modesty, leaving it up to me to decide exactly where on the sex work spectrum his work sits. In this context a shrug of the shoulder in person would have had much the same effect, indicating that the use of Emoji can go some way in compensating for a lack of visual non-verbal cues in a semi-structured interview setting.

It is debatable however, whether the use of IM and Emoji is a sufficient substitute to real life interaction and non-verbal cues for understanding and monitoring participant experience within a research interaction. Indeed, what is presented within our conversation is a filtered version of non-verbal communication, where we only shared the emotions which we chose to. Body language is often shared without intent, we may communicate a certain emotion in our words but contradict ourselves with our non-verbal cues (Mandal, 2014). Although the IM interview and its Emoji capabilities provided a form of communication beyond written text, it is limited in the sense that I could only observe what was made observable to me, and I would have missed any discomfort which was not made explicit by the participant themselves. 
Related to this, there is scope for further research to explore the additional meanings drawn from IM communication, such as the length of time taken between responses. As an example, the length of time spent typing (demonstrated by the typing indicator within most IM interfaces) may potentially reveal clues as to the depth of thought required to answer a question or prompt, which again indicates meaning outside of the typed word.

The dynamics of research interaction:

The power dynamic between a researcher and participant can impact the data collection process and the subsequent narrative presented in the written work. It is suggested that within traditional research relations the power balance is typically asymmetrical (Fahie, 2014), with the researcher credited with the thought process which constructs the study and the participants with the material to be studied (Reason, 1994). As an approach to researching with potentially vulnerable groups and addressing sensitive subject matter, this has drawn criticism for being too rigid and limiting the focus on the voices of the groups under study (Doucet and Mauthner, 2012). In a feminist approach, action is taken to minimise the power differences or inequalities between participant and researcher (Fine, 2007).

The issue of power within this research bears particular poignance when the potential vulnerability and marginalisation of the participants is considered alongside my own identity as a straight, white, university-attending male. With the research interactions described within this paper limited to those between myself and male participants, the issue of power is less likely to rest upon notions of gender inequality but steer more towards the notions of masculinity which interactions between men tend to be grounded upon (Schwalbe and Wolkomir, 2001). Connell (1987) introduces the concept of a hierarchical structure of masculine identities, with hegemonic masculinities retaining dominance over other forms of masculinity and femininity. Despite our shared male status, power differentials may have arisen 
from the position in which our masculine identity sat within this proposed hierarchy. For example, behaviours which digress from the heteronormative ideal have been considered as a subordinate form of masculinity, because of the perceived femininity of sexual interactions between men (Jewkes et al., 2015; Connell, 2018). Although male sex work and homosexuality are not inextricably linked, with straight men's involvement in sex work noted within previous research (see Ellison and Weitzer, 2016; Minichiello, Scott and Callander, 2013), there is often a presumption that their work will involve some degree of intimate contact with a male client. Even for a straight male sex worker, the hierarchy of masculinities may have influenced the power dynamic of the research interaction in the sense that their behaviour rather than their identity deviated from the societal masculine ideal (see Connell, 2018).

Significantly, the interview discussed here was with a man who seemed to largely conform to the heteronormative masculine ideal. Nathan, a straight 39-year-old white man with a strong build and a background in the armed forces and private security, described how his work involved seeing single women and heterosexual couples. On this basis, the power dynamic within the interaction may present itself as balanced, though our discussion may have revealed details of experiences or attitudes which challenged his masculine identity and thus may have upset any balance of power. The flexibility offered within my approach meant that I was able to yield power at almost every point in the research, allowing those involved to set their own terms of participation. The interview with Nathan was a particular example of this, where a remote technologically facilitated approach created a 'virtual space' between researcher and participant. Jones (2014) describes this space as removing any fear of judgement an individual may have when approaching a discussion of a sensitive issue. Within the conversational nature of the interview, Nathan felt comfortable enough to deviate from the schedule, discussing other more humorous aspects of his work and insisting that: 
I feel I could tell you some crazy stories [2]

The true potential of the IM interview in balancing the participant-researcher power dynamic may be better observed within a research relationship where there is a more recognisable power imbalance, though my experience demonstrates the methods potential to facilitate friendly and natural-feeling conversation, even when approaching sensitive topic research.

\section{Questions of validity:}

Validity within a research context is often concerned with whether the study is able to produce a truthful account of the reality of its participants (Peräkylä, 2016). The ontological and epistemological underpinnings of this work acknowledge that reality and truth is dependent on the individual. The feminist foundations upon which this research is built emphasises the importance of the reality of those who have direct experience of the issue in question (Doucet and Mauthner, 2007). The researcher's role, interpretive in nature, involves drawing from the participant an account of their own reality.

Earlier discussions highlighted the space which is created between the two parties, and the potential for this to reduce the impact that a researcher may have on the process, though this same space may have some implications for the validity of the account provided by the participant. An IM interview introduces an increase in the time expected to elapse between the question and response, which is in part responsible for this space. With more time for the participant to deliberate, and potentially filter their response to only what they want to be known, it is reasonable to assume that details could be left out. Voida and colleagues (2004) discuss this delay between the researcher's question and the participant's response and suggest that this may have brought about an element of self-censorship to their research. Of course, self-censorship is not an issue limited to online communication in itself, but with the time and 
space afforded to the participant in this technique, questions may be raised about the version of reality which is to be presented. By comparison, the telephone interview did bring with it a certain raw response, with the participant in this instance responding to prompts with only minimal pauses for thought, as is the nature with this form of communication.

The spontaneity of the response within telephone interviewing is considered to be one of its strengths by Opdenakker (2006), with initial reactions to a question or prompt perhaps revealing further details of a participant's wider feelings around a subject alongside their spoken answer (Knapik, 2006). However, in research which touches upon sensitive topics, having less time for self-censorship may mean that the participant avoids entirely an issue which they are not comfortable approaching. Censorship in this instance may present as a strength rather than something which is problematic about the approach. Indeed, Opdenakker (2006) continued their discussion by suggesting that asynchronous communication between the researcher and participant led to what they believed to be richer and more honest responses in comparison to the more spontaneous accounts.

The reality of an IM approach is that although the chance of censorship may be heightened when the participant is given the time to consider their response, it is difficult to determine whether this has a significant impact on the truthfulness of the response when compared to more synchronous methods of communication. Like with the issue of response depth, a superficial observation of the IM interview and its asynchronous nature may present as problematic, particularly when considered alongside traditionalist in-person interview methodologies. However, as discussed here, the method offers unique advantages to both researcher and participant and importantly, by facilitating participation in a way which suits them, we allow participants to present their reality on their own terms.

Concluding thoughts: 
Throughout this research, the intention has been to place an emphasis on obtaining the expertise of men engaged with transactional sex, through utilising an adaptable approach with the participants preference at heart. The adaptability was intended to help balance any issues of power, in line with previous research informed theoretically by feminist approaches. Whilst it is acknowledged that the method may not be preferable for all of those approached, the inclusion of IM took away the requirement for the participant to identify themselves; utilising instead their already established alias profiles. Whilst useful for the research at hand, the use of IM does come with limitations which have been highlighted throughout this paper. Notably, the limited ability to communicate non-verbally and any related ethical considerations should be deliberated, particularly in sensitive subject research. Conversely, it is this very disconnection between the researcher and participant which gives strength to the method, offering a space in which participants who may have avoided the study ordinarily could have their voices heard without fear of judgement.

Maintaining an adaptable research outlook led to conversations which may have been blocked by more a rigid approach. As technologically facilitated asynchronous communication becomes increasingly utilised in everyday life, perhaps as researchers we are obligated to adapt our approaches to become more fitting with the current state of communications in real life, and remain grounded in the lives of our subjects.

[1] Participants were later given the opportunity to review and amend the transcript of their interview.

[2] All Emoji are taken from Twitter and are open source. 
Reference list:

Aida, B., Fairuz Ain, H. and Woollard, J. (2019), "Collecting data via instant messaging interview and face-to-face interview: the two authors reflections", INTED 2019: The 13th annual International Technology, Education and Development Conference, 11-13 March 2019, Hotel Melia Valencia, Spain, available at: https://eprints.soton.ac.uk/427628/ (accessed 12 June 2020).

Alismail, S. and Zhang, H. (2018), "The use of Emoji in electronic user experience questionnaire: An exploratory case study”, paper presented at the 51st Hawaii International Conference on System Sciences, 2-6 January 2018, Hawaii, USA, available at: https://core.ac.uk/download/pdf/143481263.pdf (accessed 11 June 2020).

Bryce, A., Campbell, R., Pitcher, J., Laing, M., Irving, A., Brandon, J., Swindells, K. \& Safrazyan, S. (2015), "Male escorting, safety and National Ugly Mugs: queering policy and practise on the reporting of crimes against sex workers", Laing, M., Pilcher, K. and Smith, N. (Ed.s), Queer sex work, Routledge, Abingdon, pp.245-254.

Campbell, R. (2016), Not getting away with it: addressing violence against sex workers as hate crime in Merseyside ( $\mathrm{PhD}$ thesis), Durham University, Durham, available at: http://etheses.dur.ac.uk/11960/1/RosieCampbellPhDthesisrepository.pdf?DDD34 (accessed 11 June 2020).

Connell, R. (2018), “The social organization of masculinity”, Morris, E. and Blume Oeur, F. (Ed.s), Unmasking masculinities: Men and society, Sage, London, pp.5-13. 
Connell, R. W. (1987), Gender and power: Society, the person and sexual politics, Stanford University Press, Stanford.

Creswell, J. W. (2009), Research design: Qualitative, quantitative and mixed method approaches (3rd Ed.), Sage, California.

Dhir, A., Pallesen, S., Torsheim, T. and Andreassen, C. (2016), "Do age and gender differences exist in selfie-related behaviours?", Computers in Human Behavior, Vol 63, pp.549-555.

Doucet, A. and Mauthner, S. (2012), "Qualitative interviewing and feminist research", Alasuutari, P., Bickman, L. and Brannen, J. (Ed.s), The Sage handbook of social research methods, Sage, London, pp.328-343.

Doucet, A. and Mauthner, S. (2007), "Feminist methodologies and epistemologies”, Peck, D. and Bryant, C. (Ed.s), The handbook of $21^{\text {st }}$ century sociology, Sage, California, pp.36-42.

Dewey, S. and Heineman, J. (2013), "Between research and activism: Identifying pathways to inclusive research", Dewey, S. \& Zheng, T. (Ed.s), Ethical research with sex workers: Anthropological approaches, Springer, New York, pp.57-96.

Durante, C. (2016), “Adapting nonverbal coding theory to mobile mediated communication: An Analysis of Emoji and other digital nonverbals" (Masters thesis), Liberty University: Virginia, available at https://digitalcommons.liberty.edu/masters/408/ (accessed 11 June 2020). 
Ellison, G. and Weitzer, R. (2016), “The dynamics of male and female street prostitution in Manchester, England”, Men and Masculinities, Vol. 20 No. 2, pp.181-203.

Emojipedia (2019a), “Person facepalming”, available at: https://emojipedia.org/face-palm/, (accessed 11 June 2020).

Emojipedia (2019b), “Man shrugging”, available at: https://emojipedia.org/man-shrugging/, (accessed 11 June 2020).

Fahie, D. (2014), "Doing sensitive research sensitively: Ethical and methodological issues in researching workplace bullying”, International Journal of Qualitative Methods, pp.19-36.

Fedyuk, O. and Zentai, V. (2018), "The interview in migration studies: A step towards a dialogue and knowledge co-production?", Zapata-Barrero, R. and Yalaz, E. (Ed.s), Qualitative research in European migration studies, Cham, Springer, pp.171-188.

Fine, M. (2007), “Feminist Designs for Difference,” Handbook of Feminist Research: Theory and Praxis. Thousand Oaks, Sage, pp. 613-620.

Fontes, T. and O’Mahony, M. (2008), “In-depth interviewing by instant messaging”, Social Research Update, Vol. 53.

Home Office (2004), "Paying the price: a consultation paper on prostitution”, Home Office, London. 
Home Office (2006), “A coordinated prostitution strategy”, Home Office, London.

Home Office (2008), “Tackling demand for prostitution: A review”, Home Office, London.

Jewkes, R., Morrell, R., Hearn, J., Lundqvist, E., Blackbeard, D., Lindegger, G., Quayle, M. Sikweyiya, Y. and Gottzen, L. (2015), "Hegemonic masculinity: Combining theory and practice in gender interventions", Culture, Health and Sexuality, Vol. 17 No. 2, pp.96-111.

Jones, M. (2014), "Methodological and ethical issues related to qualitative telephone interviews on sensitive topics”, Nurse Researcher, Vol. 21 No. 4, pp.32-37.

Jones, T. and Newburn, T. (2001), “Widening Access: Improving Police Relations with Hard to Reach Groups. Police Research Series Paper 138”, Home Office, London.

Knapik, M. (2006), “The qualitative research interview: Participants' responsive participation in knowledge making”, International Journal of Qualitative Methods, Vol. 5 No. 3, pp.77-93.

Krumer-Nevo, M. (2009), "From voice to knowledge: participatory action research, inclusive debate and feminism. International Journal of Qualitative Studies in Education, Vol 22 No.3, pp. 279-296.

Mandal, F. (2014), "Nonverbal communication in humans", Journal of Human Behavior in the Social Environment, Vol. 24 No. 4, pp.417-421.

Mariampolski, H. (2001), Qualitative market research, Sage, California. 


\begin{abstract}
Minichiello, V., Scott, J. and Callander, D. (2013), "New pleasures and old dangers: reinventing male sex work", The Journal of Sex Research, Vol. 50, pp.263-275.

O’Neill, M. (2010), “Cultural criminology and sex work: Resisting regulation through radical democracy and participatory action research (PAR)", Journal of Law and Society, Vol. 37 No. 1, pp.210-232.
\end{abstract}

Opdenakker, R. (2006), “Advantages and disadvantages of four interview techniques in qualitative research", Forum: Qualitative Social Research, Vol. 7 No. 4.

Partington, G. (2001), “Qualitative research interviews: identifying problems in technique”, Issues in Educational Research, Vol. 11 No. 2, pp.32-44.

Peräkylä, A. (2016), "Validity in qualitative research", Silverman, D. (Ed.), Qualitative Research, Sage, London, pp.413-428.

Pitcher J. (2015), “Sex work and modes of self-employment in the informal economy: diverse business practices and constraints to effective working”, Social policy and society: a journal of the Social Policy Association, Vol. 14 No. 1, pp.113-123.

Pitcher, J. \& Wijers, M. (2014). "The impact of different regulatory models on the labour conditions, safety and welfare of indoor-based sex workers", Criminology and Criminal Justice, Vol 14 No. 5, pp.549-564. 
Punch, K. (2014), Introduction to social research: Quantitative \& qualitative approaches, Sage, London.

Reason, P. (1994), Participation in human inquiry, Sage, London.

Rodriguez, L. (2018), "Methodological challenges of sensitive topic research with adolescents", Qualitative Research Journal, Vol. 18 No. 1, pp.22-32.

Rubin, H. and Rubin, I. (2005), Qualitative interviewing (2 ${ }^{\text {nd }}$ edn): The art of hearing data. Sage, California.

Sagar, T., Jones, E., Jones, D. and Clark L. (2014), Sex work research Wales 2010-2014, Unpublished.

Sanders, T., Scoular, J., Pitcher, J. and Cunningham, S. (2018), Internet sex work: Beyond the Gaze, Palgrave, London.

Silverman, D. (2000), Doing qualitative research: A practical handbook, Sage, California.

Schwalbe, M., and Wolkomir, M. (2001), "The masculine self as problem and resource in interview studies of men”, Men and Masculinities, Vol. 4 No. 1, pp.90-103.

Time (2015), "Oxford's 2015 word of the year is this Emoji”, available at: https://time.com/4114886/oxford-word-of-the-year-2015-emoji/ (accessed 11 June 2020). 
Van der Meulen, E. (2011), “Action research with sex workers: Dismantling barriers and building bridges", Action Research, Vol. 9 No. 4, pp.370-384.

Voida, A., Mynatt, E., Erickson, T. \& Kellogg, W. (2004), “Interviewing over instant messaging”, in CHI '04 Extended Abstracts on Human Factors in Computing Systems (CHI EA '04), New York, pp.1344-1347.

Weitzer, R. (2018), “Resistance to sex work stigma”, Sexualities, Vol. 21 No. 5-6, pp.717-729.

Whowell, M. (2010), “Male sex work: Exploring regulation in England and Wales”, Journal of Law and Society, Vol. 37, pp.125-144. 